\title{
Highly Conductive Graphene Electronics by Inkjet Printing
}

\author{
DONGBIN ZHU (1), ${ }^{1,3}$ ZHUXIAN WANG, ${ }^{1}$ and DONGMING ZHU ${ }^{2}$ \\ 1.-School of Mechanical Engineering, Hebei University of Technology, Tianjin 300130, People's \\ Republic of China. 2.-Zunhua Power Supply Branch Company, State Grid Jibei Electric Power \\ Company Limited, Beijing 100053, People's Republic of China. 3.-e-mail: \\ zhudongbin@hebut.edu.cn
}

Graphene is currently emerging as an alternative to traditional conductive materials, such as copper and silver because of its excellent electrical conductivity and earth's carbon abundance. Graphene can be applied in many different electronic fields with different manufacturing methods to meet their specific requirements, which promote the development of advanced manufacturing technology in graphene electrical applications. Inkjet printing, as an environmentally friendly, low-cost and simple-to-operate advanced manufacturing method, has broad development prospects especially in the field of flexible electronics. In this review, several factors affecting the electrical conduction property of graphene applications in the inkjet-printed graphene process are listed as follows: the preparation method of ink, material and treatment of substrate, thickness of print, and annealing, especially whether a coffee ring is produced. In addition, this paper also cites some examples of inkjet-printed graphene in electrical conductivity. In order to continuously improve the procedure designs of graphene electronics fabrication, more accurate relationships between electrical conductivity of graphene and these parameters can be built. Based on the excellent prospect of inkjet printing technology in the field of conductive electronics, there will be some further research about the perfect implementation of graphene's electrical conductivity.

\section{Graphic Abstract}

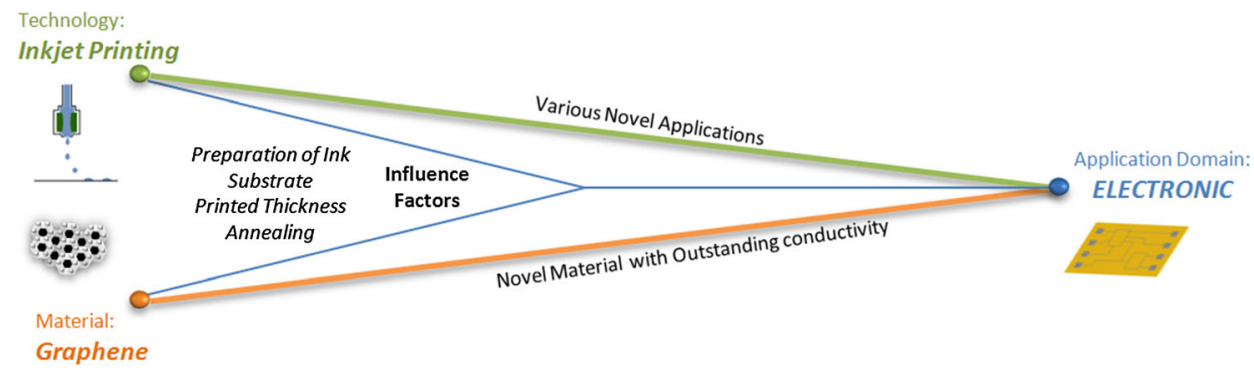

Key words: Graphene, inkjet printing, conductivity, electronics

\section{INTRODUCTION}

Since its discovery in 2004 by Andre Geim and Konstantin Novoselov at the University of Manchester, graphene as the thinnest two-dimensional 
carbon material gradually became one of the hottest scientific topics, when its bright industrial development prospect attracted the attention of the world. In 1962 it was observed originally on electron microscopes, but the studies only focused on metal substrates. The later rediscovery, isolation and characterization of graphene resulted in the two winning the Nobel Prize in Physics in 2010 "for groundbreaking experiments regarding the two-dimensional material graphene." In the conductive field, the usually used conductive metals have long histories with their particular properties to apply for various propose, while their shortcomings cannot be neglected. Recently, carbon nanotubes (CNTs), as a rising nano-material, have already been widely studied as conductive printable inks, ${ }^{1-4}$ while poor dispersibility limits its applications. Compared with CNT, graphene is easier to pattern, easier to observe, and its layer number is easier to calculate under an optical microscope. Among the known available materials, graphene is strongest and nearly transparent, and it can conduct heat and electricity efficiently, promoting a step forwards in the field of manufacture of electronic devices. In Fig. 1, it is obvious to see a growing trend of JCR articles with keywords, graphene electronics, from 2004 and updated to 2018, and the above reasons are not enough to explain this phenomenon. Graphene exhibits good hydrophobic properties and good ferromagnetism, especially with massless electrons and an anomalous quantum Hall effect, which are both unique to graphene. ${ }^{5}$ With the above properties, graphene brings many applications into the field of electriconics (Fig. 2).

The higher requirements for the electrical conductivity caused by industry development accelerate both the improvement of manufacturing technology and research of new materials. Inkjet printing, as an advanced manufacturing technology, is a multi-discipline technology, in which the intended pattern can be achieved by depositing ink on substrates with relatively high production speed.

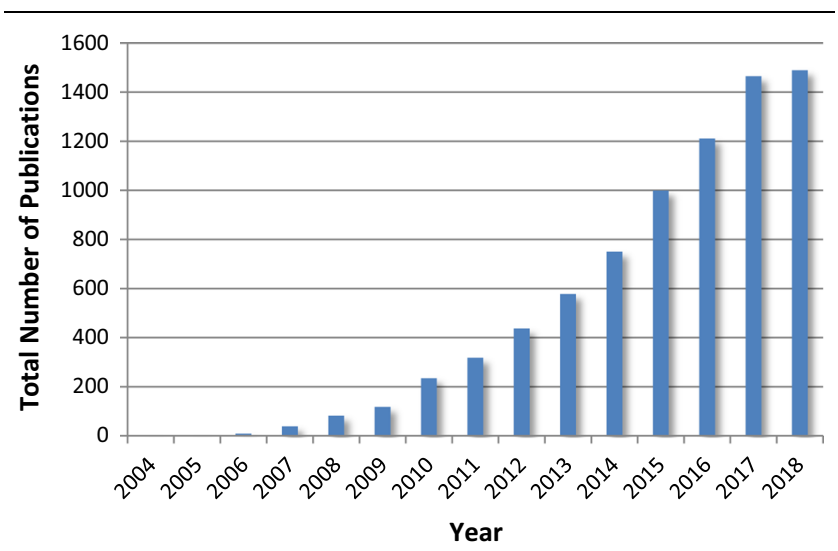

Fig. 1. Number of JCR articles per year, as reported by the Journal of Citation Report, Web of Science (http://apps.webofknowledge.c om), from 2004 and updated to 2018 retrieved via the keyword "graphene electronics" in the topic of the paper.
Therefore, printed electronic technology is environmentally friendly, simple to operate, low cost, and avoids waste, when inkjet printing tasks can be achieved by relative motion between the nozzle and the substrate and computer controlled flexible deposition of conductive inks. The combination of printing technique with the electronic conductivity of graphene is a potentially disruptive technology with broad development prospects and application advantages. In the research of Finn et al., ${ }^{6}$ graphene ink dissolved in NMP ( $N$-methyl pyrrolidone) was used to print a conductive pattern on PET (polyethylene terephthalate) foils. Based on numerous experiments, ${ }^{7,8} \mathrm{Li}$ et al. ${ }^{9}$ and Östling et al., ${ }^{10}$ proposed a plan for effective integration of graphene inks applied to inkjet printing technology, contributing to a reliable mass production of highquality 2D films/patterns. ${ }^{11}$ Recent correlated research has demonstrated inkjet printing of graphene for the fabrication of functional devices such as FET (field effect transistor), ${ }^{12}$ valley filters, ${ }^{13}$ actuators, ${ }^{14,15}$ thin film transistors, ${ }^{16}$ transistors, ${ }^{17,18}$ touch screens, and solar panels. ${ }^{5}$

This review first summarizes the high electrical conductivity of inkjet-printed graphene, compared with the traditional conductive materials. Inkjetprinted graphene possesses a broad growth prospect with its superior properties, especially in electrical applications. In addition, several factors from the production process that affect the electrical conductivity of printed graphene are demonstrated, and some electrical applications of printed graphene are also exhibited.

\section{GRAPHENE}

\section{Characteristics of Graphene}

Graphene is a two-dimensional constituent element for common graphite forms ${ }^{19}$ in a six-

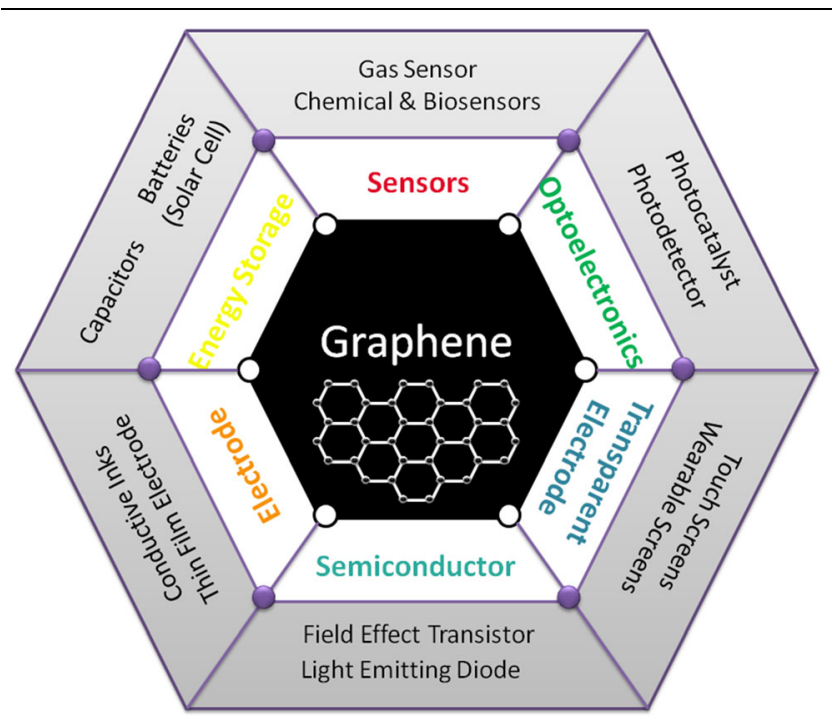

Fig. 2. Electrical applications of graphene. 
membered ring of carbon atoms. ${ }^{20}$ The size of graphene sheets experimentally can vary from tens of nanometers to centimeters. After nearly 50 years of research and development, graphene is widely used for a plethora of diverse applications in materials, electronics, energy, biology and other fields, ${ }^{21-24}$ making graphene one of the most valuable nanomaterials in the world.

Graphene is one of the hitherto strongest materials ever found, and single-layered graphene shows a tensile strength up to $130 \mathrm{GPa}{ }^{20}$ while its specific surface area is about $2630 \mathrm{~m}^{2} \mathrm{~g}^{-1} \cdot{ }^{25}$ Graphene also exhibits a quantum Hall effect at room temperature,${ }^{26}$ good ferromagnetism, ${ }^{27}$ and better thermal conductivity than $\mathrm{CNTs}^{28}$ and metals such as silver ${ }^{29}$ and copper. ${ }^{30}$ In addition, low areal density and corking elastic property of graphene make it possible to maintain the initial size even after large strain. $^{31}$

In the research of graphene, one of the biggest challenges is how to produce high-quality graphene. Until now there were three types of typical graphene production methods, top-down exfoliation, bottom-up growth, ${ }^{32-34}$ and unclassified approaches (Fig. 3). The top-down production of graphene means graphite exfoliation by physical, chemical, and electrochemical methods, ${ }^{31}$ such as the "Scotch tape method", in which both quality and yield of graphene cannot be available. ${ }^{32}$ Chemical vapor deposition (CVD), as a typical "bottom-up growth" method for the large batches production of graphene ${ }^{31}$ is mainly used for high-quality, large-area graphene production. ${ }^{32}$ However, this technique increases high requirements because the working atmosphere is under continuous high temperature and the process is complex and multi-staged. Singleand few-layer graphene can be grown epitaxially not only by CVD of hydrocarbons on metal substrates $^{35,36}$ but by thermal decomposition of SiC. ${ }^{37-40}$ Even with so many advantages and such a good development prospect of graphene production, low yield and high cost of these methods still hinder its better applications. ${ }^{32}$

\section{The Electrical Conductivity of Graphene}

Electrical resistivity, as the reciprocal of conductivity, is a physical quantity to describe the hindrance to current through the conductor, usually defined as follows:

$$
\rho=R \cdot A / L
$$

where $\rho$ is the resistivity $(\Omega \mathrm{m}), R$ is the measured resistance, $A$ is the cross-sectional area and $L$ is the film length. ${ }^{41}$ Equation 1 is the basic principle of electrical conductivity and usually used to test resistivity rating of material by the relationship of measured resistance, cross-sectional area and film length. Actually, for printed electronics the most commonly used parameter is the sheet resistance, which is only related to resistivity and thickness and primarily can be measured by four-point probe. ${ }^{42}$

Highly conductive property of graphene is caused by some micro-level reasons. From electronics perspective, graphene is a zero-overlap material with holes and electrons as charge carries. Because of the zero effective electron/hole mass in graphene, its charge carriers exhibit large intrinsic mobility, $2.5 \times 10^{5} \mathrm{~cm}^{2} / \mathrm{Vs}$ in experimental measurement, and electron/hole can travel over micrometers without scattering at room temperature ${ }^{43,44}$ Conductivity of graphene is related to electron mobility and carrier density, both of which usually are negatively correlated. ${ }^{43}$ According to research on conductivity of graphene, its mobility decreases from $10^{5} \mathrm{~cm}^{2} / \mathrm{Vs}$ to $10^{4} \mathrm{~cm}^{2} / \mathrm{Vs}$ when the charge carrier increases from $10^{12} / \mathrm{cm}^{2}$ to $10^{13} / \mathrm{cm}^{2.45,46}$ From an atomic perspective, each carbon atom of graphene has four unpaired electrons at the outermost layer, three of

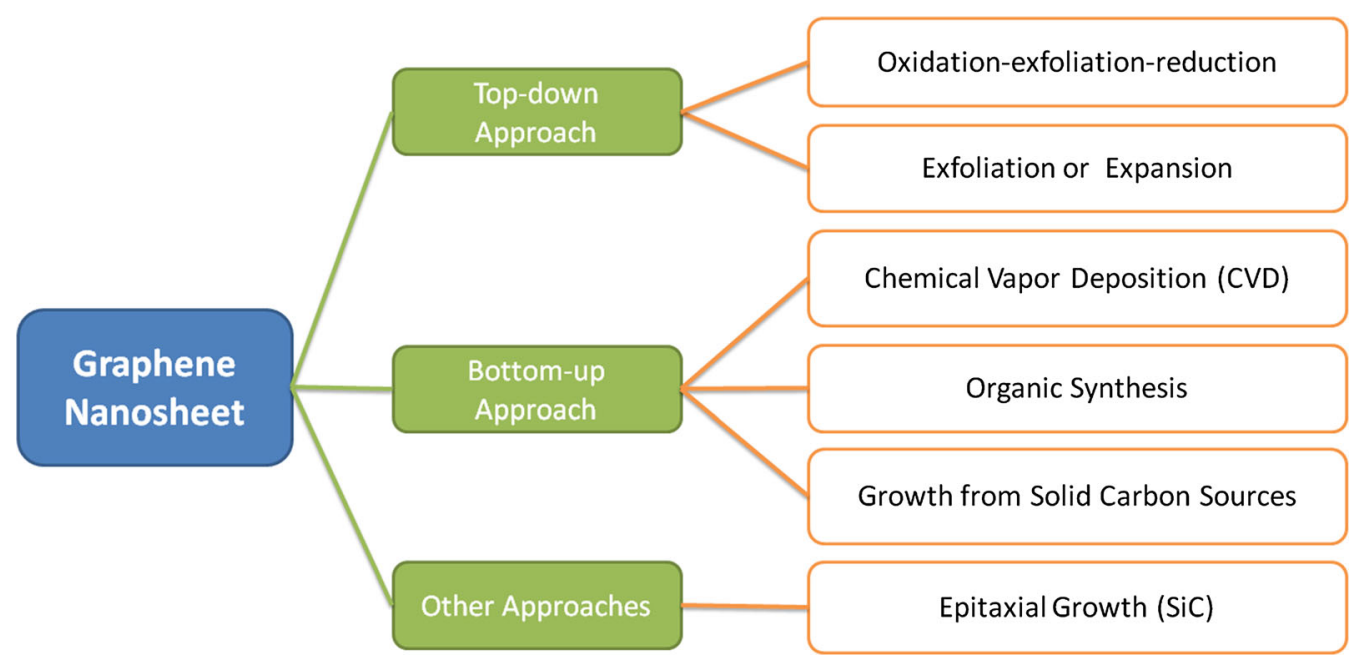

Fig. 3. Synthesis methods of graphene from different precursors. 
which are linked to three adjacent carbon atoms by $\sigma$-bonds on the two-dimensional plane. ${ }^{31}$ The fourth electron located outside the graphene sheet is freely available for electronic conduction and is connected to free electrons of another carbon atom by $\pi$ (pi)bond. ${ }^{31}$ According to some further research, such high electron mobility graphene is closely related to the Dirac point and quantum tunneling effect in graphene, especially the charge transfer which makes the Dirac points of graphene higher than the Fermi level, increases the carrier concentration and promotes electrical conductivity of the graphene. ${ }^{47}$

Different production methods also cause different graphene conductivity. Large, uniform, single-layer graphene can be produced by CVD with a lower sheet resistance (ca. $1000 \Omega / \mathrm{sq}$ ) compared with the graphene films prepared by the chemical modification of graphene. ${ }^{48-51}$ As for the reduction of graphene oxide (GO) methods, graphene films is fully reduced from GO when incomplete reduction causes a relatively inferior electrical performance, ${ }^{52,53}$ but consequently inkjet-printing of pristine graphene films has significant advantages in electronic applications. ${ }^{54}$ These GO materials, which can be mass synthesized by the improved Hummer's method and excellent dispersion in water, maintains well the superior electrical conductivity of graphene with the reduction process by chemical or thermal procedures. ${ }^{55}$ According to the references, graphene flakes can be exfoliated by ultrasonication in select solvents ${ }^{56}$ and superacids ${ }^{57}$ or using additives such as surfactants ${ }^{58}$ and stabilizing polymers ${ }^{59,60}$ to achieve the size of graphene $<10 \mu \mathrm{m}^{2}$ in area. Furthermore, while small size is essential for stable inkjet printing, increasing flaketo-flake junctions are added in percolating films, resulting in a higher resistance compared with that of CVD-grown or mechanically exfoliated graphene ${ }^{54}$ see Fig. 4 . Recent theoretical ${ }^{61}$ and experimental $^{62-64}$ studies indicated that introducing $1 D$ conductive bridges, such as silver nanowires

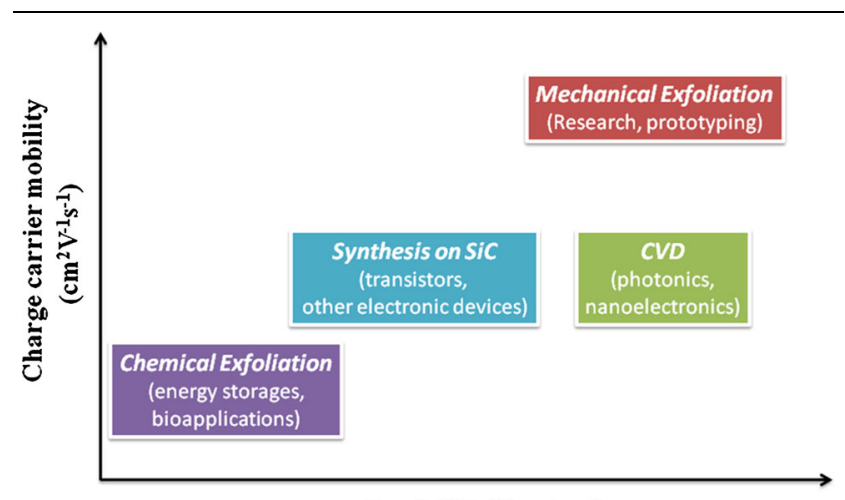

Crystallite Size $(\mu \mathrm{m})$

Fig. 4. Several methods of production of graphene electronics.
(AgNWs), enhance the electron transport capacity of graphene films, meaning more possibilities for their conductive applications.

\section{INKJET PRINTING FORMATION}

Inkjet printing is a method for depositing liquid droplets on substrates. As a direct-write technique, it was originally used to transfer data of a printed pattern from a computer onto substrates, such as paper, polymers, metals, and ceramics, becoming a popular digital fabrication method of biotechnology $^{65-67}$ and electronics. ${ }^{42,68,69}$ With no contact between the print-head and the substrate, small droplets of ink are ejected from the print-head nozzle directly onto the desired position of substrate by digital control, ${ }^{70,71}$ line and space dimensions arrive at minimum value, $20 \mu \mathrm{m}$, with high resolution. ${ }^{72,73}$ According to the state of the sprayed droplet, inkjet printing usually can be divided into continuous inkjet printing (CIJ), ${ }^{74,75}$ drop-on-demand (DOD) inkjet printing, ${ }^{76}$ and the latter is widely used for graphene inks.

To achieve stable droplet formation in the inkjet printing process, the viscosity and surface tension of the ink formulation must be carefully tailored. ${ }^{77}$ In addition, to achieve proper morphology of the printed patterns, the wetting and drying properties of the ink also must meet corresponding requirements. ${ }^{78}$ In 2012 , Torrisi et al. ${ }^{16}$ from the University of Cambridge achieved inkjet printing of graphene electronics. According to their study, the ink, prepared from liquid exfoliated graphene and suspended in the solvent NMP, is well jetted even with inappropriate set parameters. ${ }^{16}$ Coleman et al. ${ }^{79-81}$ paid attention to the inks prepared by exfoliating graphene in NMP and applied dispersions based on the controlled low- and high-speed centrifugation coupled with sediment re-suspension. According to Ref. 54 Secor et al. designed ink with relatively low surface tension applicable to flexible electronics fabricated from low-surface-energy substrates. Figure 5 demonstrates a usual preparation method of graphene inks, exfoliation of graphite in ethanol and EC (ethylene carbonate), ${ }^{60}$ and the characteristics of printed patterns (Fig. 5). After graphite powder was exfoliated in ethanol/EC by probe ultrasonication, the remaining large graphite flakes were removed by centrifugation (Fig. 5a and b), and a solid containing graphene and EC was flocculated and collected after mixing with $\mathrm{NaCl}(\mathrm{aq})$ (Fig. 5c). Then this graphene/EC solid was washed and dried and subsequently dispersed in select organic solvents (Fig. 5d and e). Finally, it was deposited onto the well-defined substrate of $\mathrm{Si} / \mathrm{SiO}_{2}$, and the patterns observed with SEM and AFM are shown in Fig. 5f and g, respectively. This stable graphene ink rinted lines on HMDS-treated $\mathrm{Si} / \mathrm{SiO}_{2}$ substrate, yielding a line width of $\sim 60 \mu \mathrm{m}$ without undesirable coffee ring effects. ${ }^{54}$ 
(a)

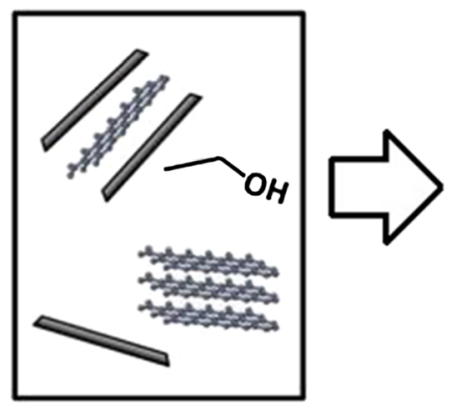

(e)

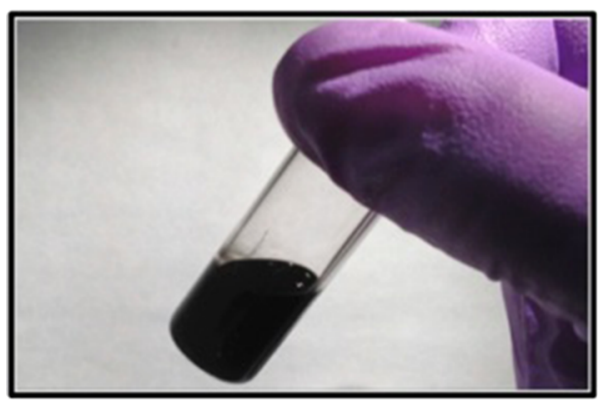

(b)

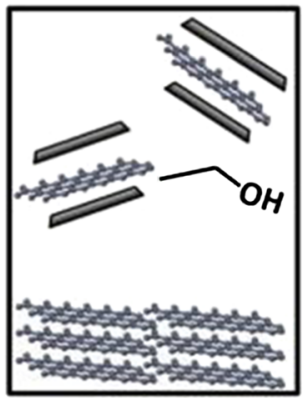

(c)

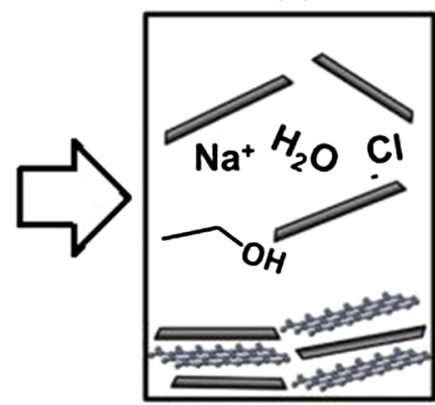

(f)

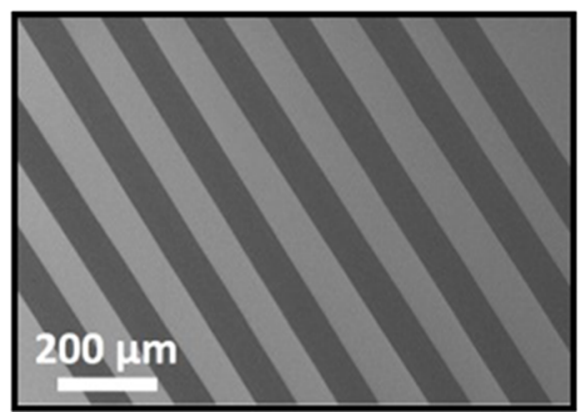

(d)

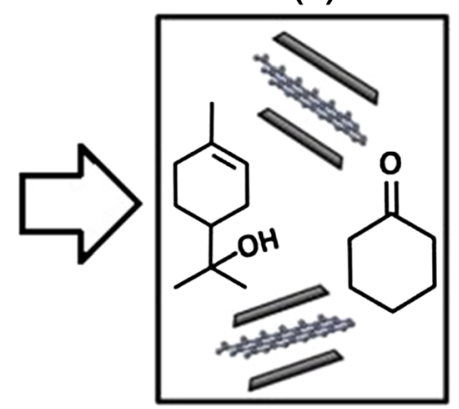

(g)

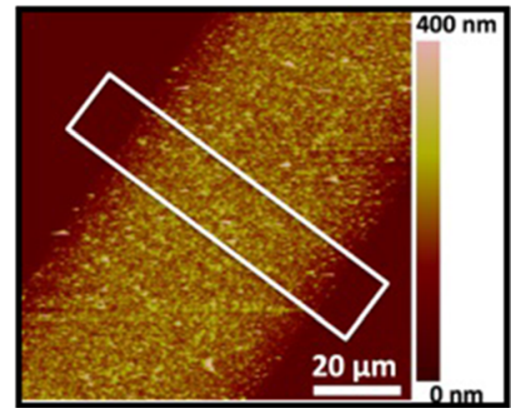

Fig. 5. Schematic illustration of the graphene ink preparation procedure and its morphology of inkjet-printed features. (a) Graphene is exfoliated from graphite powder in ethanol/EC. Graphene/EC powder is then isolated (b) to move the remaining large graphite flakes and (c) salt-induced flocculation of graphene/EC. (d) The prepared ink for inkjet printing. (e) Vial of the prepared graphene ink. Scanning electron micrographs of (f) multiple printed lines. (g) An atomic force microscopy (AFM) image of a single line. Reprinted with permission. ${ }^{54}$ Copyright 2013 American Chemical Society.

\section{FACTORS AFFECTING ELECTRICAL CONDUCTIVITY OF PRINTED GRAPHENE}

In the inkjet printing process, the basic requirements for conductive inks are similar to other inks: good printability, super rheological property, good adhesion to specific substrates. In order to obtain optimal printing performance, important parameters such as viscosity, surface tension, wettability and adhesion to substrate should be adjusted on demand. However, these parameters are usually controlled by direct parameters of the printing process. With the requirement of high electrical conductivity of the printed patterns, the content of the conductive nanomaterial must be high and the content of non-conducting materials, such as organic polymeric stabilizers, wetting agents and adhesion promoters, should be controlled. ${ }^{42}$ The ink used for printed electronics usually adds an aqueous or organic liquid vehicle and various additives to optimize performance. ${ }^{19,72,73,76}$ The following discussion is on several factors of four steps: the method and additives used in preparation of ink, the material used and treatment of substrate, thickness of print, and annealing.

\section{Preparation of Ink}

In the entire production process of inkjet-printed graphene electrical components, the preparation of graphene ink, as the first step, influences the final electrical conductivity. As an emerging 2D material, there are many developed preparation methods, and scholars have prepared various graphene inks for their experiments, resulting in different conductive properties. RGO (reduced graphene oxide) ink, widely used in inkjet printing, has poor electrical properties that limit its application in the field of electronics (Table I). In addition, when planning the procedure of graphene ink jet printing, there are the following points to note: low efficiency of printing caused by low-density graphene, complicated and time-consuming procedure caused by technology such as solvent exchange, and even contamination caused by using additives. From Table I, the conductivity of RGO inks are usually lower than pristine graphene ink produced by exfoliation, while different additives used in exfoliation methods also affect the conductivity of printed patterns.

Graphene types listed in the Table I are classified according to the production methods and additives of graphene inks. For printable pristine graphene inks, there are two general strategies applied for inkjet printing, shown schematically in Fig. $6 \mathrm{a}$ and b. Graphene can be exfoliated directly in NMP and subsequently printed, ${ }^{6,16}$ while graphene can also be stable with EC in most organic solvents. ${ }^{89}$ According to Fig. 6c, it is obvious that grapheneEC is better at electrical conductivity, when the other performances are ignored. In conclusion, it is obvious that the method used to produce graphene 
Table 1. Conductivity of different graphene type with different annealing method

\begin{tabular}{|c|c|c|c|c|}
\hline No & Graphene type & Annealing process & $\begin{array}{l}\text { Best electrical } \\
\text { performance }\end{array}$ & References \\
\hline 1 & RGO & $200^{\circ} \mathrm{C}$ for $12 \mathrm{~h}$ in $\mathrm{N}_{2}$ & NA & $\mathrm{Le}^{82}$ \\
\hline 2 & RGO & $\begin{array}{c}350^{\circ} \mathrm{C} \text { for } 1 \mathrm{~h} \text { under a } \mathrm{H}_{2} / \mathrm{Ar} \\
\text { atmosphere }\end{array}$ & $\sigma=70 \mathrm{~S} / \mathrm{m}$ & $\operatorname{Lim}^{83}$ \\
\hline 3 & RGO & $\sim 200^{\circ} \mathrm{C} 10 \mathrm{~min}$ & $\sigma \sim 800 \mathrm{~S} / \mathrm{m}$ & Kong $^{84}$ \\
\hline 4 & RGO & $400^{\circ} \mathrm{C}$ for $3 \mathrm{~h}$ & $\sigma=900 \mathrm{~S} / \mathrm{m}$ & Huang ${ }^{55}$ \\
\hline 5 & RGO & $80^{\circ} \mathrm{C}$ for $1 \mathrm{~h}$ & $\sigma=1500 \mathrm{~S} / \mathrm{m}$ & Dua $^{85}$ \\
\hline 6 & RGO & Vapor deposition in hydrazine & $\sigma=5500 \mathrm{~S} / \mathrm{m}$ & Shin $^{14}$ \\
\hline 7 & RGO(AgNPs) & $250^{\circ} \mathrm{C}$ for $30 \mathrm{~min}$ & $R=4 \times 10^{3} \Omega \mathrm{cm}$ & $\mathrm{Li}^{86}$ \\
\hline 8 & Exfoliated graphene (NMF) & $170^{\circ} \mathrm{C}$ for $5 \mathrm{~min}$ & $\sigma=100 \mathrm{~S} / \mathrm{m}$ & Torrisi $^{16}$ \\
\hline 9 & Exfoliated graphene (NMF) & NONE & $\sigma=3000 \mathrm{~S} / \mathrm{m}$ & Finn ${ }^{6}$ \\
\hline 10 & Exfoliated graphene (DMF) & $375-400^{\circ} \mathrm{C}$ for $0.5-1 \mathrm{~h}$ in air & $\sigma \sim 3400 \mathrm{~S} / \mathrm{m}$ & $\mathrm{Li}^{8}$ \\
\hline 11 & Exfoliated graphene (CO2) & $300^{\circ} \mathrm{C}$ for $30 \mathrm{~min}$ & $\sigma=9240 \mathrm{~S} / \mathrm{m}$ & $\mathrm{Gao}^{87}$ \\
\hline 12 & Exfoliated graphene (Ethanol and EC) & $250^{\circ} \mathrm{C}$ for $30 \mathrm{~min}$ & $\sigma=25,000 \mathrm{~S} / \mathrm{m}$ & Secor ${ }^{54}$ \\
\hline 13 & $\begin{array}{c}\text { Intercalation and liquid phase exfoliation of } \\
\text { raw graphite }\end{array}$ & $400^{\circ} \mathrm{C}$ for $30 \mathrm{~min}$ & $R_{\mathrm{sq}}=30 \mathrm{k} \Omega / \square$ & Arapov $^{88}$ \\
\hline
\end{tabular}

(a)

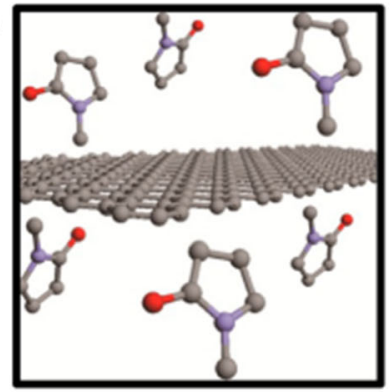

(b)

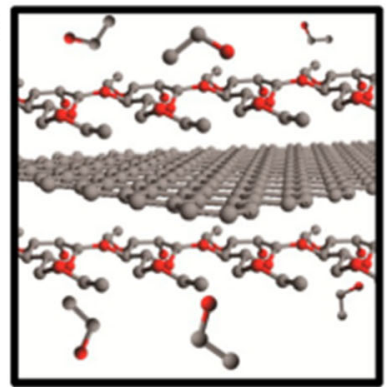

(c)

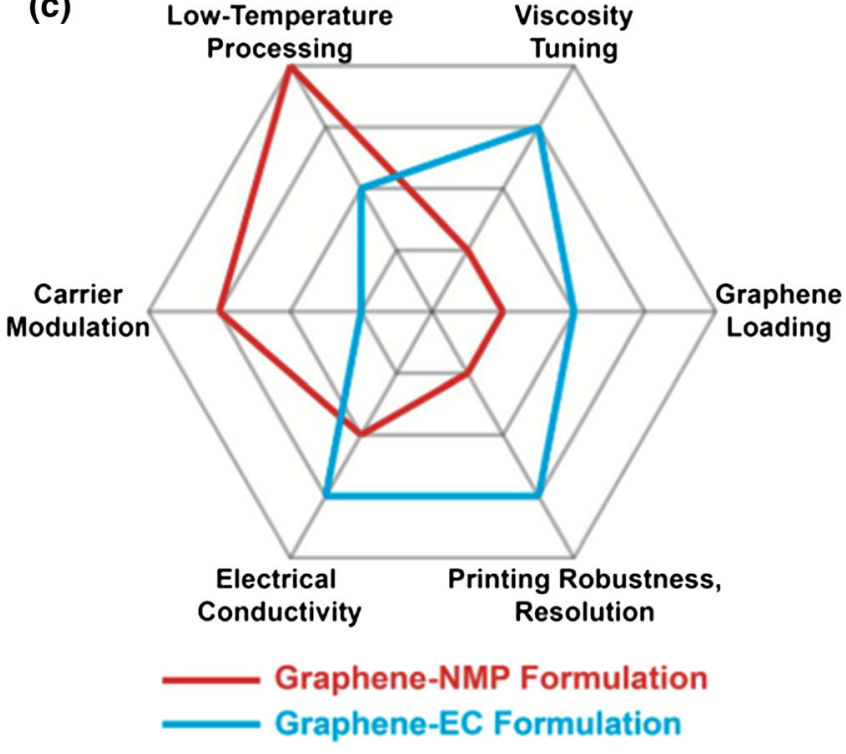

Fig. 6. Two types of pristine graphene inks for printed electronics. (a, b) Illustration of two different chemistries for pristine graphene inks, NMP (a) and EC (b). (c) Illustration of the quality comparison between graphene-NMP formulation and graphene-EC formulation. Reprinted with permission. ${ }^{89}$ Copyright 2015 American Chemical Society.

inks affects the electrical conductivity; however, to ensure the best route of graphene inks still needs a large number of systematic experiments and systematic data analysis.

\section{Substrate}

The material used as substrate in inkjet printing also influences the electrical conductivity. Capasso $^{90}$ observed that the difference of electrical performance on different substrates is due primarily to differences in substrate thermal properties. According to Fig. $7,{ }^{91}$ although the sheet resistance changed with pulse energy, glass used as substrate usually caused a higher sheet resistance, while the sheet resistance of graphene dropped onto PET and PEN is at a low degree. In addition, the surface quality, especially whether coffee rings are formed, influences the electrical properties of printed patterns. The coffee ring is a physical phenomenon produced after droplet evaporation, which is also an essential process to acquire desired deposited patterns. ${ }^{92}$ The coffee ring regularly arises as a defect in inkjet printing, since it means heterogeneous liquid deposition and heterogeneous particle size distribution. As a result, there is still substantial work underway to explore its mechanisms and 

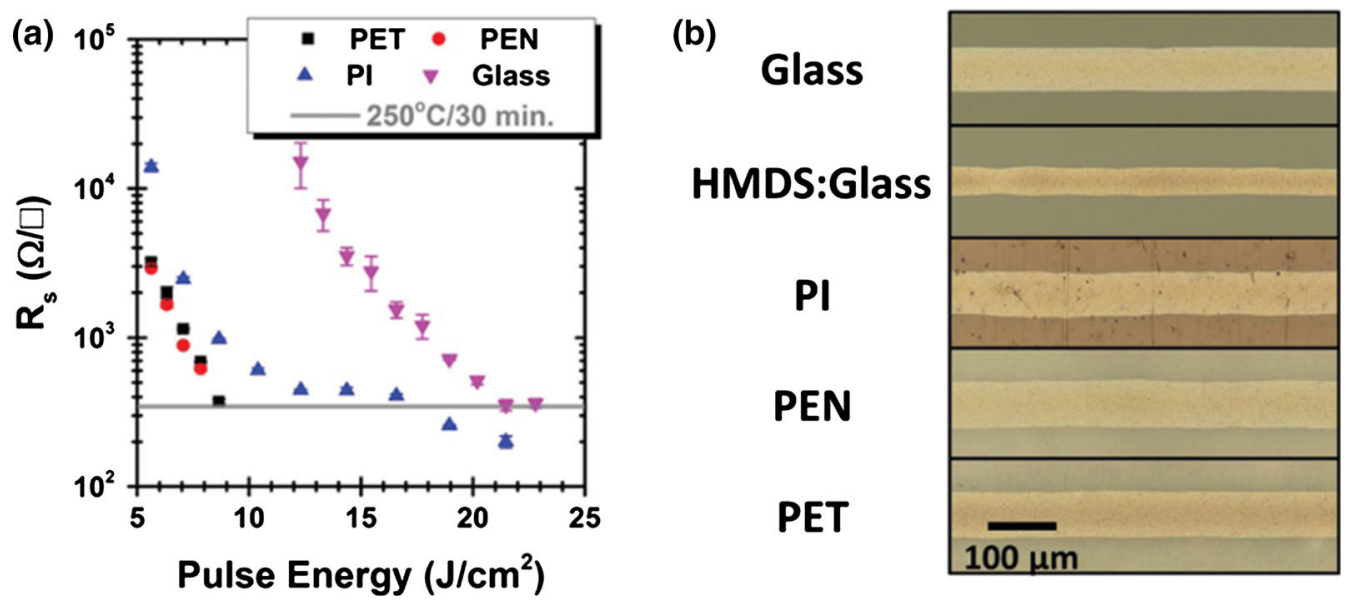

Fig. 7. Versatility of IPL annealing for graphene patterns. (a) Sheet resistance change of graphene films for different substrates (PET, PEN, PI, and glass) with the growth of pulse energy. (b) Optical microscopy images of lines on five different surfaces with a drop pitch of $35 \mu \mathrm{m}$. Reprinted with permission. ${ }^{91}$ Copyright 2015 John Wiley and Sons.
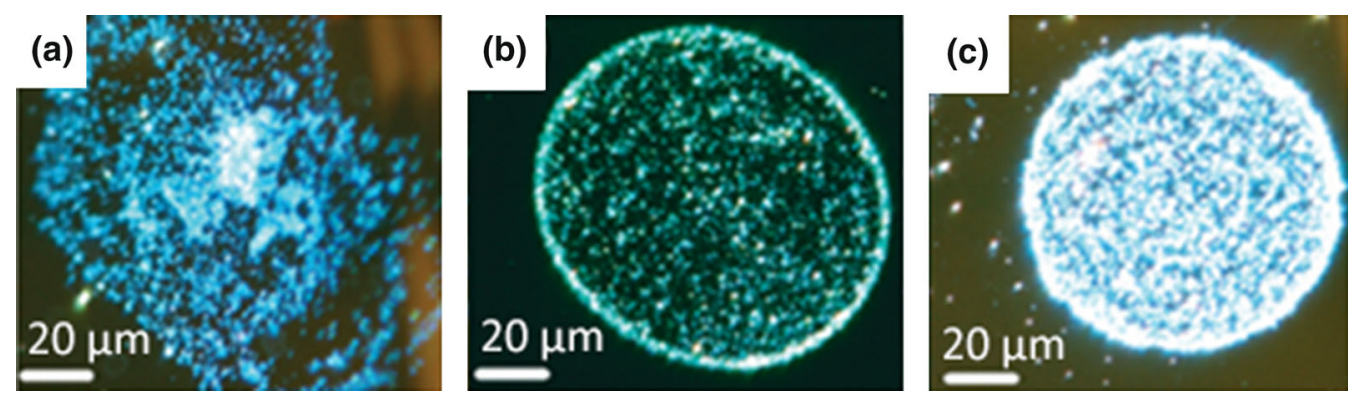

Fig. 8. Dark-field optical micrograph of inkjet-printed drops on (a) plasma-cleaned, (b) pristine, and (c) HMDS-treated substrate. Reprinted with permission. ${ }^{16}$ Copyright 2012 American Chemical Society.

prevention. ${ }^{93,94}$ To improve the electrical conductivity of graphene patterns, it is necessary to reduce the possibility of coffee ring generation to create better properties and a better electric conductivity. However, according to Ref. 90 when the ink type is pristine graphene, the coffee ring effect is not observed in the printed electrodes, even if substrate type is different, such as printing paper, glass, and HMDS-treated PET. Torrisi et al. ${ }^{16}$ visualized the inkjet-printed droplets with an optical microscope, Fig. 8, which shows that the printed bright greenblue colored drops in Fig. 8c at $\sim 90 \mu \mathrm{m}$ in diameter are smaller than the colored drops in Fig. $8 a$ and b. In addition, Fig. 8 also shows that coffee rings emerge when printing on pristine $\mathrm{SiO}_{2}$ and do not exist on HMDS-treated $\mathrm{SiO}_{2}$ substrate. Furthermore, influential factors in the deposition process are substrate properties and coffee rings, as well as flow characteristics of drops, ${ }^{91}$ thermal conductivity ratio between the substrate and liquid, ${ }^{89}$ surface charge of the substrate and particle surfaces, ${ }^{95}$ and even the shape of the droplet particles. ${ }^{87,96}$

\section{Printed Thickness}

Gao et al. ${ }^{87}$ ran a series of tests to verify the relation between the electrical conductivity and the number of printed layers and drew a conclusion, shown in Fig. 9, that the resistance of graphene is related to the number of printed layers. As a result, the resistance is proportional to the thickness, which confirms Eq. 1. As the printed layers increase, the line thickness grows in proportion, causing a decrease of resistivity, which means a better electrical conductivity. So in the inkjet printing process of graphene electronic components, the number of printed layers ranges (in Gao's report, the range is 20-30), after surface quality is achieved.

\section{Annealing}

Similar to the traditional manufacturing method, the printed pattern usually cannot be used as an electrode without post-treatment, which also plays an important role in the electrical conductivity of printed graphene. Annealing is a post-treatment that changes the physical and sometimes chemical properties of a material to increase its ductility and reduce its hardness, making it more workable. The gas environment of the annealing process also affects the final performances of produced electronics. For example, annealing in N2 or Ar causes better properties than annealing in atmosphere 

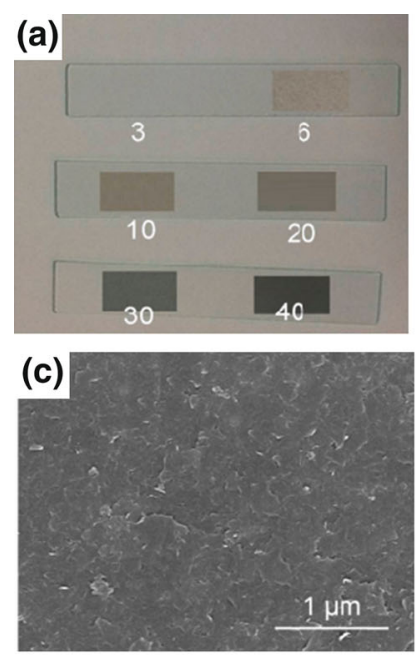
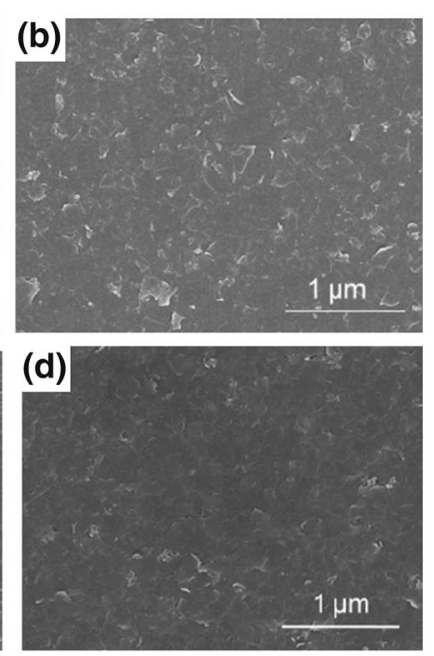

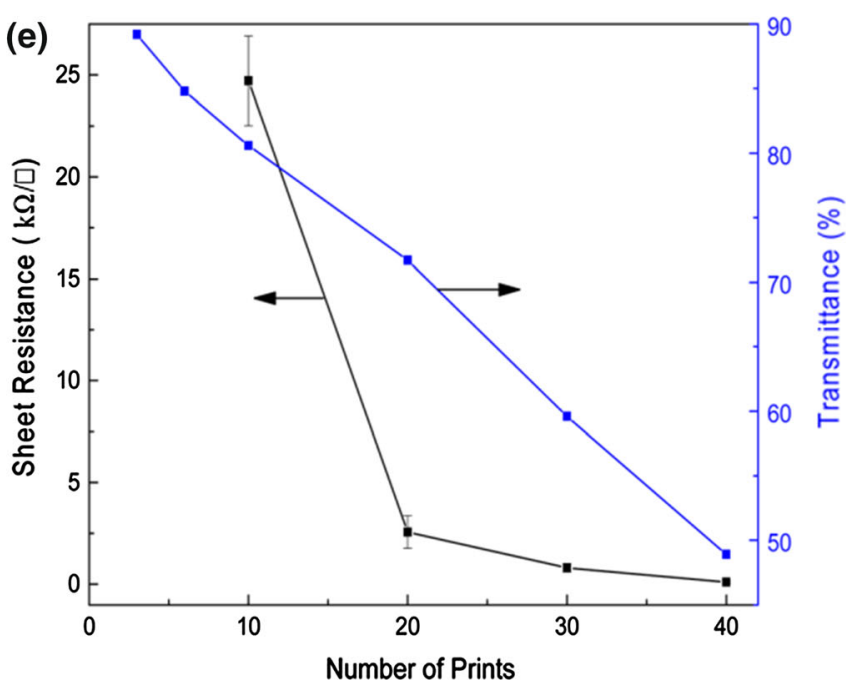

Fig. 9. Inkjet-printed graphene conductive patterns. (a) Photograph of the printed patterns after various printing passes (from 3 to 40 ). (b-d) Scanning electron microscopy (SEM) images of the printed patterns after 10, 30, and 40 printing passes, respectively. (e) Sheet resistance and transmittance (at $\lambda=550 \mathrm{~nm}$ ) of the printed patterns with increasing numbers of printing passes. Reprinted with permission. ${ }^{87}$ Copyright 2014 American Chemical Society.
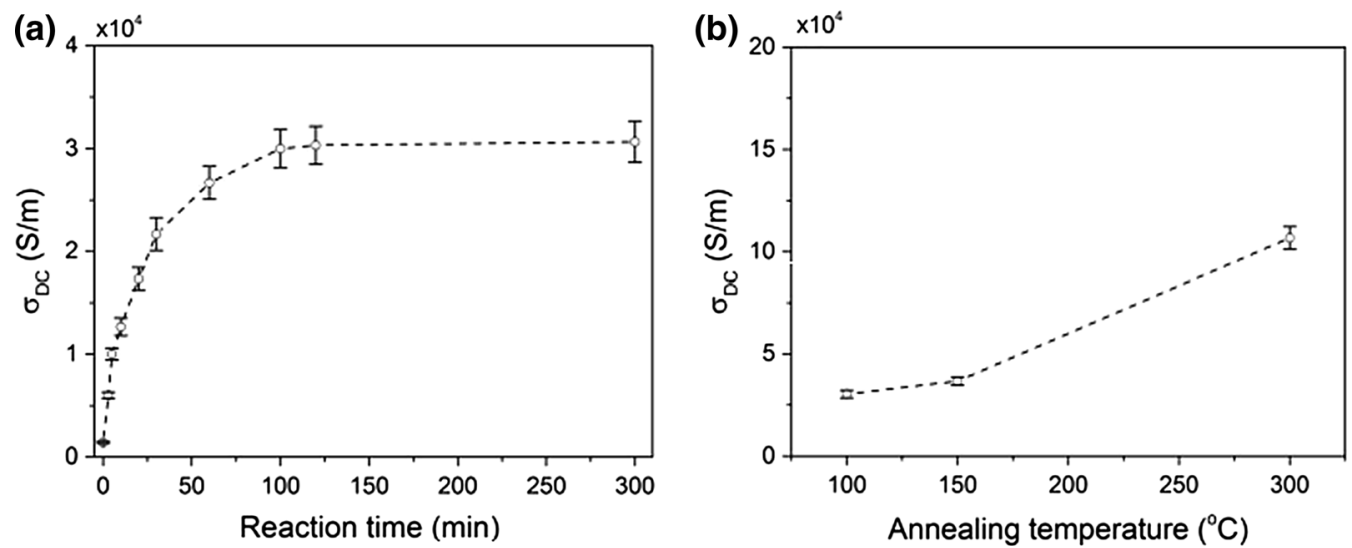

Fig. 10. (a) Conductivity against the annealing temperature for a fixed annealing time of $30 \mathrm{~min}$. (b) Variation of conductivity with annealing duration for a fixed annealing temperature of $250^{\circ} \mathrm{C}$. Reprinted with permission. ${ }^{99}$ Copyright 2017 Elsevier.

environment. ${ }^{97,98}$ In the annealing process, the material is first heated, then maintained at a suitable temperature for a suitable amount of time, and finally cooled. So the set of the temperature and time is important to the result. A similar type of graphene ink with different annealing temperature and time causes different surface topography of patterns.

References 99,100 obtained similar conclusions: suitable temperature and time of annealing process, $250-350^{\circ} \mathrm{C}$ and more than $25 \mathrm{~min}$, respectively, just like the character in Fig. 10. Considering the changes in annealing process, reasons can be analyzed. In Fig. 10a, based on a constant annealing time, when the set temperature is lower than $250^{\circ} \mathrm{C}$, the post-treatment degree increases with the increase in set temperature, resulting in a positive change in conductivity; however, when the temperature exceeds $400^{\circ} \mathrm{C}$, undesired changes of material cause poor resistivity. In Fig. 10b, with a fixed annealing temperature of $250^{\circ} \mathrm{C}$, in the first $25 \mathrm{~min}$ of the annealing process, the post treatment is ongoing as the time increases and is finished in $25 \mathrm{~min}$, so after $25 \mathrm{~min}$ the resistivity basically no longer changes with time. In conclusion, the temperature and time of annealing process are also important parameters for the conductivity of the printed pattern.

\section{APPLICATIONS}

Because of its excellent properties, graphene has been widely explored for applications in various fields, and most effort has focused on the direction of graphene-based electronics, as in companies such as Intel and IBM. ${ }^{19}$ With the traditional production methods, graphene has already been applied in electrical fields, such as gas ${ }^{101-103}$ and energy storage $^{25}$ in photonics and flexible 
electronics, ${ }^{104-107}$ solar cells, ${ }^{108-110}$ supercapacitors $^{111,112}$ and light-emitting devices, ${ }^{113}$ touch screens, ${ }^{114}$ photodetectors, ${ }^{115-118}$ electromagnetic (EM) absorbers, ${ }^{119}$ and ultrafast lasers. ${ }^{120,121}$ With the development of nanotechnology, the trend of materials research is towards microstructure. As a result, advanced manufacturing technologies enter the field of nanomaterials production. In the inkjetprinted electronics process, graphene usually is the main material or additive of the ink to obtain superior electrical conductive properties. With its material strength and flexibility, graphene ink can be used in e-paper or wearable electronics ${ }^{122}$ (Fig. 11a), extending the range of applications. Given the large surface area and sensitivity to doping, graphene is a logical material for sensing applications. ${ }^{123,124}$ Graphene electrodes have also been applied to detect various chemicals ${ }^{125}$ (Fig. 11b), including nitrogen dioxide, hydrogen peroxide, carbon monoxide, and water, ${ }^{126}$ because the electron transport through graphene is highly sensitive to the adsorption of gas molecules. ${ }^{127}$ Printed multifunctional integrated systems based on wearable graphene electronic/optoelectronic devices can monitor bio-signals of the user in real time ${ }^{128}$ (Fig. 11c). Combining advanced manufacturing techniques with highly conductive graphene, the production of electronic devices has great potential for development.

\section{OUTLOOK}

Researchers in the fields of physics, chemistry, and materials are committed to the exploration into the numerous applications of graphene, with still ongoing research activities. The main research directions are listed as follows: exploring the preparation of large-area, high-quality graphene materials and their industrialization, discovering the excellent properties of graphene materials and their potential application value, developing applications that reflect the many "ideal" properties of graphene, etc. Among all the studies, to choose and design a suitable forming process is one of the most effective focuses. With the development of the artificial intelligence and automation industry, printed electronics, as the common product type of electronics devices and systems, begins to occupy an increasing market share. However, with different printing technology, graphene materials are available for different situations, such as screen printing for lowresolution components or devices and with highviscosity paste, gravure printing on rigid substrates, flexographic printing for thin functional layers, and inkjet printing for laboratory research as well as customized and specialized components or devices.

Among them, inkjet printing is probably one of the most promising techniques to achieve the research target of graphene, which does not mean that there is no challenge. To find suitable graphene
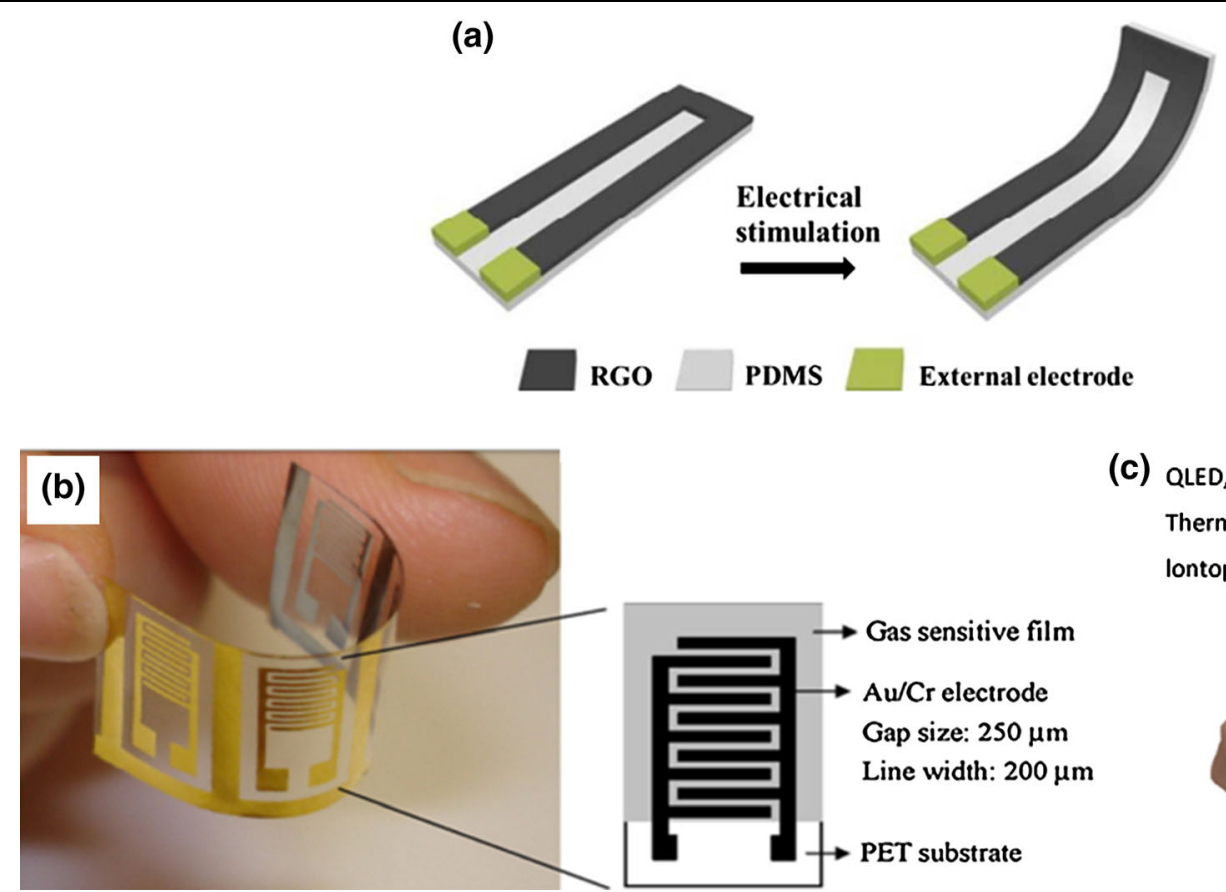

(c) QLED, Strain gauge

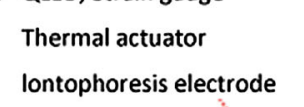

Wireless data

transmission

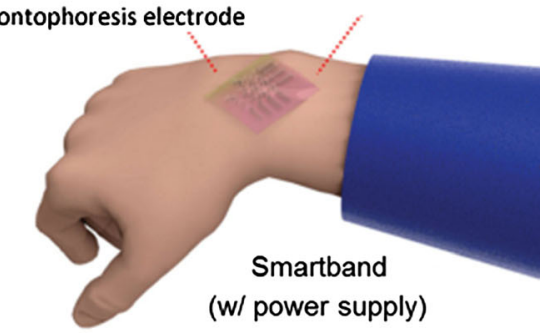

Fig. 11. (a) Soft actuator of the RGO/PDMS bilayer actuator under electrical stimulation with printed RGO electrodes. Reprinted with permission. ${ }^{122}$ Copyright 2016 American Chemical Sociey, (b) Flexible RGO gas sensor. Reprinted with permission. ${ }^{125}$ Copyright 2015 Elsevier, (c) Wearable and transparent graphene electronic/optoelectronics system Reprinted with permission. ${ }^{28}$ Copyright 2015 John Wiley and Sons. 
ink production methods requires a series of experiments and research. When moving one step further in the process chain to the actual deposition and printing, another apparent challenge emerges. In order to acquire the required inkjet printed pattern, the rheological properties of the graphene ink must be adjusted on demand, which means the requirements for the fundamental characters of graphene ink, for example, well-defined sizes and thicknesses of dispersed graphene nanosheets, tailored viscosities at both high- and low-boiling-point, as well as nontoxic solvents. Furthermore, the resolution of the printing process must be improved. As the last step, post-treatment for inkjet-printed graphene, usually annealing, has a great influence on the applications with various temperature and time length. In addition, the graphene ink production also allows for some fine-tuning of electronic properties by the addition of molecules or polymers that provide supplementary functions and/or control of doping levels, thus, almost infinite possibilities exist.

However, compared with traditional manufacturing technologies, the printing technique is still at an early stage of development. Although, based on solution processing, it is easy to imagine the integration of various layered crystals in functional devices, so it is still unclear whether this will finally develop industrially relevant processes or products. Several issues still must be overcome for the optimization of graphene inkjet printing. The first problem is that the surface quality of the printed pattern is not always easy to guarantee, especially with the coffee ring phenomenon, which cannot be eliminated with quantitative design, but can be improved by numerous pre-experiments. In addition, the solvent is essential for graphene ink preparation, but it also causes some issues, such as its toxicity and low viscosity which have a strong effect on the jetting performance, ${ }^{11}$ the removal of high-boiling-point solvent in annealing stage that severely limits the type of substrate. Last but not least, the issue with the scalability needs to be faced. Compared to pristine graphene, the nanocomposites easily prepared from graphene or its derivatives by modification with polymers, conducting polymers, surfactants, and other nanomaterials ${ }^{129,130}$ have superior electrical conductivity. ${ }^{31} \mathrm{As}$ a result, the research on conductive graphene become much harder and more sophisticated. Because, as in other rising materials, the industrialization of graphene is the goal of all efforts in research, with further studies on the perfect realization of inkjet-printed graphene's electrical conductivity, better procedure designs of graphene production will emerge.

\section{ACKNOWLEDGMENTS}

This work is supported by a grant from Natural Science Foundation of Hebei Province (CN) (Grant No. E2018202200).

\section{REFERENCES}

1. Z. Fan, T. Wei, G. Luo, and F. Wei, J. Mater. Sci. 40, 18 (2005).

2. A. Denneulin, J. Bras, A. Blayo, B. Khelifi, F.R. Dherbey, and C. Neuman, Nanotechnology 20, 38 (2009).

3. P. Beecher, P. Servati, A. Rozhin, A. Colli, V. Scardaci, S. Pisana, T. Hasan, A.J. Flewitt, J. Robertson, and G.W. Hsieh, J. Appl. Phys. 102, 4 (2007).

4. W. Tong, J. Ruan, Z. Fan, G. Luo, and W. Fei, Carbon 45, 13 (2007).

5. Nat. Nanotechnol. 5, 755 (2010). https://doi.org/10.1038/nn ano.2010.224.

6. D.J. Finn, M. Lotya, G. Cunningham, R.J. Smith, D. McCloskey, J.F. Donegan, and J.N. Coleman, J. Mater. Chem. C 2, 5 (2013). https://doi.org/10.1039/C3TC31993H.

7. J. Li, F. Ye, S. Vaziri, M. Muhammed, M.C. Lemme, and M. Östling, Carbon 50, 8 (2012). https://doi.org/10.1016/j.carb on.2012.03.011.

8. J. Li, F. Ye, S. Vaziri, M. Muhammed, M.C. Lemme, and M. Östling, Adv. Mater. 25, 29 (2013). https://doi.org/10.1002/ adma.201300361.

9. J. Li, M.C. Lemme, and M. Östling, ChemPhysChem 15, 16 (2014).

10. J. Li, M.M. Naiini, S. Vaziri, M.C. Lemme, and M. Östling, Adv. Funct. Mater. 24, 6524 (2014). https://doi.org/10.100 2/adfm.201400984.

11. F. Bonaccorso, A. Bartolotta, J.N. Coleman, and C. Backes, Adv. Mater. 28, 29 (2016).

12. Y.M. Lin, C. Dimitrakopoulos, K.A. Jenkins, D.B. Farmer, H.Y. Chiu, A. Grill, and P. Avouris, Science 327, 5966 (2010). https://doi.org/10.1126/science.1184289.

13. T. Fujita, M.B.A. Jalil, and S.G. Tan, Appl. Phys. Lett. 97, 4 (2010). https://doi.org/10.1063/1.3473725.

14. K.Y. Shin, J.Y. Hong, and J. Jang, Chem. Commun. 47, 30 (2011). https://doi.org/10.1039/c1cc12913a.

15. W. Jiang, D. Niu, H. Liu, C. Wang, T. Zhao, L. Yin, Y. Shi, B. Chen, Y. Ding, and B. Lu, Adv. Funct. Mater. 24, 48 (2014). https://doi.org/10.1002/adfm.201402070.

16. F. Torrisi, T. Hasan, W. Wu, Z. Sun, A. Lombardo, T.S. Kulmala, G.W. Hsieh, S. Jung, F. Bonaccorso, P. Paul, D. Chu, and A.C. Ferrari, ACS Nano 6, 4 (2012).

17. T. Low and F. Guinea, Nano Lett. 10, 9 (2010).

18. V.V. Cheianov, V. Fal'ko, and B.L. Altshuler, Science 315, 5816 (2007).

19. A.K. Geim and K.S. Novoselov, Nat. Mater. 6, 11 (2009). h ttps://doi.org/10.1142/9789814287005_0002.

20. X. Sun, H. Sun, H. Li, and H. Peng, Adv. Mater. 25, 37 (2013). https://doi.org/10.1002/adma.201301926.

21. S. Goenka, V. Sant, and S. Sant, J. Control. Release 173, 1 (2014).

22. A.K. Geim, Science 324, 5934 (2009).

23. M.S. Artiles, C.S. Rout, and T.S. Fisher, Adv. Drug Deliv. Rev. 63, 14 (2011).

24. P. Nguyen and V. Berry, J. Phys. Chem. Lett. 3, 8 (2012).

25. M.D. Stoller, S. Park, Y. Zhu, J. An, and R.S. Ruoff, Nano Lett. 8, 10 (2008). https://doi.org/10.1021/nl802558y.

26. K.S. Novoselov, Z. Jiang, Y. Zhang, S.V. Morozov, H.L. Stormer, U. Zeitler, J. Maan, G.S. Boebinger, P. Kim, and A.K. Geim, Science 315, 5817 (2007).

27. Y. Wang, Y. Huang, Y. Song, X. Zhang, Y. Ma, J. Liang, and Y. Chen, Nano Lett. 9, 1 (2009).

28. X. Zhao, B. Song, W. Fan, Y. Zhang, and Y. Shi, J. Alloys Compd. 665, 271 (2016). https://doi.org/10.1016/j.jallcom.2 015.12 .126$.

29. D. Zhu and M. Wu, J. Electron. Mater. 47, 9 (2018).

30. J.H. Seol, I. Jo, A.L. Moore, L. Lindsay, Z.H. Aitken, M.T. Pettes, X. Li, Z. Yao, R. Huang, D. Broido, N. Minqo, R.S. Ruoff, and L. Shi, Science 328, 5975 (2010).

31. S.K. Vashist and J.H.T. Luong, Carbon 84, 519 (2015). h ttps://doi.org/10.1016/j.carbon.2014.12.052.

32. F. Bonaccorso, A. Lombardo, T. Hasan, Z. Sun, L. Colombo, and A.C. Ferrari, Mater. Today 15, 12 (2012). 
33. M. Xu, T. Liang, M. Shi, and H. Chen, Chem. Rev. 113, 5 (2013).

34. M. Chhowalla, H.S. Shin, G. Eda, L.J. Li, K.P. Loh, and Z. Hua, Nat. Chem. 5, 4 (2013).

35. A. Nagashima, Surf. Sci. Lett. 291, 93 (1993).

36. T.A. Land, T. Michely, R.J. Behm, J.C. Hemminger, and G. Comsa, Surf. Sci. 264, 3 (1992).

37. C. Berger, Z.M. Song, T.B. Li, X.B. Li, A.Y. Ogbazghi, R. Feng, Z.T. Dai, A.N. Marchenkov, E.H. Conrad, P.N. First, and W.A. de Heer, J. Phys. Chem. B 108, 52 (2004).

38. I. Forbeaux, J.M. Themlin, and J.M. Debever, Phys. Rev. B 58,24 (1998).

39. C. Berger, Z. Song, X. Li, X. Wu, N. Brown, C. Naud, D. Mayou, T. Li, J. Hass, A. Marchenkov, E. Conrad, P. First, and W. Heer, Science 312, 5777 (2006).

40. T. Ohta, A. Bostwick, T. Seyller, K. Horn, and E. Rotenberg, Science 313, 5789 (2006).

41. K.S. Novoselov, A.K. Geim, S.V. Morozov, D. Jiang, Y. Zhang, S.V. Dubonos, I.V. Grigorieva, and A.A. Firsov, Science 306, 5696 (2004).

42. A. Kamyshny and S. Magdassi, Small 10, 17 (2014).

43. Z. Cui, Printed Electronics Materials Technologies and Applications (Hoboken: Wiley, 2016), p. 450.

44. J. Gilot, M.M. Wienk, and R.A.J. Janssen, Org. Electron. $12,4(2011)$.

45. A. Puetz, T. Stubhan, M. Reinhard, O. Loesch, E. Hammarberg, S. Wolf, C. Feldmann, H. Kalt, A. Colsmann, and U. Lemmer, Sol. Energy Mater. Sol. Cells 95, 2 (2011).

46. J. Ajuria, I. Etxebarria, W. Cambarau, U. Muñecas, R. Tena-Zaera, J.C. Jimeno, and R. Pacios, Energy Environ. Sci. 4, 2 (2011).

47. H. Liu, Y. Liu, and D. Zhu, J. Mater. Chem. 21, 10 (2011). h ttps://doi.org/10.1039/C0JM02922J.

48. A. Kasry, M.A. Kuroda, G.J. Martyna, G.S. Tulevski, and A.A. Bol, ACS Nano 4, 7 (2010).

49. H.A. Becerril, J. Mao, Z. Liu, R.M. Stoltenberg, Z. Bao, and Y. Chen, ACS Nano 2, 3 (2008).

50. Y.X. Xu, H. Bai, G.W. Lu, C. Li, and G.Q. Shi, J. Am. Chem. Soc. 130,18 (2008).

51. X.S. Li, Y.W. Zhu, W.W. Cai, M. Borysiak, B.Y. Han, D. Chen, R.D. Piner, L. Colombo, and R.S. Ruoff, Nano Lett. 9 , 12 (2009).

52. C.G. Navarro, R.T. Weitz, A.M. Bittner, M. Scolari, A. Mews, M. Burghard, and K. Kern, Nano Lett. 7, 11 (2007).

53. C. Mattevi, G. Eda, S. Agnoli, S. Miller, K.A. Mkhoyan, O. Celik, D. Mastrogiovanni, G. Granozzi, E. Garfunkel, and M. Chhowalla, Adv. Funct. Mater. 19, 16 (2009).

54. E.B. Secor, P.L. Prabhumirashi, K. Puntambekar, M. Geier, and M.C. Hersam, J. Phys. Chem. Lett. 4, 8 (2013).

55. L. Huang, Y. Huang, J. Liang, X. Wan, and Y. Chen, Nano Res. 4, 7 (2011). https://doi.org/10.1007/s12274-011-0123-z.

56. Y. Hernandez, M. Lotya, D. Rickard, S.D. Bergin, and J.N Coleman, Langmuir 26, 5 (2010).

57. N. Behabtu, J.R. Lomeda, M.J. Green, A.L. Higginbotham, A. Sinitskii, D.V. Kosynkin, D. Tsentalovich, A.N.G. ParraVasquez, J. Schmidt, and E. Kesselman, Nat. Nanotechnol. $5,6(2010)$

58. A.A. Green and M.C. Hersam, Nano Lett. 9, 12 (2009).

59. J.W.T. Seo, A.A. Green, A.L. Antaris, and M.C. Hersam, J. Phys. Chem. Lett. 2, 9 (2011). https://doi.org/10.1021/j z2003556

60. Y.T. Liang and M.C. Hersam, J. Am. Chem. Soc. 132, 50 (2010).

61. C. Jeong, P. Nair, M. Khan, M. Lundstrom, and M.A. Alam, Nano Lett. 11, 11 (2011). https://doi.org/10.1021/nl203041n.

62. I.N. Kholmanov, C.W. Magnuson, A.E. Aliev, H. Li, B. Zhang, J.W. Suk, L.L. Zhang, E. Peng, S.H. Mousavi, and A.B. Khanikaev, Nano Lett. 12, 11 (2012).

63. M.S. Lee, K. Lee, S.Y. Kim, H. Lee, J. Park, K.H. Choi, H.K. Kim, D.G. Kim, D.Y. Lee, S. Nam, and J.U. Park, Nano Lett. 13, 6 (2013). https://doi.org/10.1021/nl401070p.

64. R. Chen, S.R. Das, C. Jeong, M.R. Khan, D.B. Janes, and M.A. Alam, Adv. Funct. Mater. 23, 5150 (2013). https://doi. org/10.1002/adfm.201300124.
65. S.V. Murphy and A. Anthony, Nat. Biotechnol. 32, 8 (2014).

66. B.-J. de Gans, P.C. Duineveld, and U.S. Schubert, Adv. Mater. 16, 3 (2004).

67. K. Rak-Hwan, K. Dae-Hyeong, X. Jianliang, K. Bong Hoon, P. Sang-Il, P. Bruce, G. Roozbeh, Y. Jimin, L. Ming, and L. Zhuangjian, Nat. Mater. 9, 11 (2010).

68. A. Teichler, J. Perelaer, and U.S. Schubert, J. Mater. Chem. C 1, 10 (2013).

69. D. Lupo, W. Clemens, S. Breitung, and K. Hecker, Applications of Organic and Printed Electronics, ed. E. Cantatore (Springer: New York, 2012), p. 1.

70. J.G. Korvink, P.J. Smith, and D.Y. Shin, Inkjet-Based Micromanufacturing (Weinheim: Wiley-VCH, 2012), p. 371. https://doi.org/10.1002/9783527647101.

71. G. Cummins and M.P.Y. Desmulliez, Circuit World 38, 4 (2012).

72. G. Abellan, C. Marti-Gastaldo, A. Ribera, and E. Coronado, Acc. Chem. Res. 48, 6 (2015).

73. S.Z. Butler, S.M. Hollen, C. Linyou, C. Yi, J.A. Gupta, H.R. Gutiérrez, T.F. Heinz, H. Seung Sae, H. Jiaxing, and A.F. Ismach, ACS Nano 7, 4 (2013).

74. B. Derby, Annu. Rev. Mater. Res. 40, 1 (2010).

75. S. Magdassi, The Chemistry of Inkjet Inks (Singapore: World Scientific Publishing Company, 2009), p. 356. http s://doi.org/10.1142/6869.

76. P. Calvert, Chem. Mater. (2001). https://doi.org/10.1021/c $\mathrm{m} 0101632$

77. D. Zhu, R. Chu, X. Zhang, E. Cheng, Z. Zhang, Y. Qu, C. Sun, and G. Duan, Chin. J. Mech. Eng. 53, 13 (2017). h ttps://doi.org/10.3901/JME.2017.13.108.

78. S. Dan, S. Vivek, and Colloids, Langmuir 24, 5 (2008).

79. U. Khan, A. O'Neil, M. Lotya, S. De, and J.N. Coleman, Small 6, 7 (2010). https://doi.org/10.1002/smll.200902066.

80. Y. Hernandez, V. Nicolosi, M. Lotya, F.M. Blighe, Z. Sun, S. De, I.T. McGovern, B. Holland, M. Byrne, Y.K. Gun'Ko, J.J. Boland, P. Niraj, G. Duesberg, S. Krishnamurthy, R. Goodhue, J. Hutchison, V. Scardaci, A.C. Ferrari, and J.N. Coleman, Nat. Nanotechnol. 3, 9 (2008). https://doi.org/10. 1038/nnano.2008.215.

81. J.N. Coleman, Acc. Chem. Res. 46, 1 (2013).

82. L.T. Le, M.H. Ervin, H. Qiu, B.E. Fuchs, and W.Y. Lee, Electrochem. Commun. 13, 4 (2011).

83. S. Lim, B. Kang, D. Kwak, W.H. Lee, J.A. Lim, and K. Cho, J. Phys. Chem. C 116, 13 (2012).

84. D. Kong, L.T. Le, Y. Li, J.L. Zunino, and W. Lee, Langmuir 28, 37 (2012)

85. P.J. Yunker, M.A. Lohr, T. Still, A. Borodin, D.J. Durian, and A.G. Yodh, Phys. Rev. Lett. 110, 3 (2013).

86. L. Li, Y. Guo, X. Zhang, and Y. Song, J. Mater. Chem. A 2, 44 (2014).

87. Y. Gao, W. Shi, W. Wang, Y. Leng, and Y. Zhao, Ind. Eng. Chem. Res. 53, 43 (2014). https://doi.org/10.1021/ie502675z.

88. K. Arapov, R. Abbel, G. de With, and H. Friedrich, Faraday Discuss. 173, 323 (2014).

89. E.B. Secor and M.C. Hersam, J. Phys. Chem. Lett. 6, 4 (2015).

90. A. Capasso, A.E. Del Rio Castillo, H. Sun, A. Ansaldo, V. Pellegrini, and F. Bonaccorso, Solid State Commun. 224, 53 (2015). https://doi.org/10.1016/j.ssc.2015.08.011.

91. E.B. Secor, B.Y. Ahn, T.Z. Gao, J.A. Lewis, and M.C. Hersam, Adv. Mater. 27, 42 (2015).

92. S. Sacanna, D. Pine, and G.-R. Yi, Soft Matter 9, 34 (2013).

93. V. Tallapally, D. Damma, and S.R. Darmakkolla, Chem. Commun. 55, 11 (2019).

94. S.V. Morozov, K.S. Novoselov, F. Schedin, D. Jiang, A.A. Firsov, and A.K. Geim, Phys. Rev. B 72, 20 (2005).

95. J. Kim and B.M. Weon, Appl. Phys. Lett. 113, 183704 (2018). https://doi.org/10.1063/1.5049606.

96. P. He and B. Derby, Adv. Mater. Interfaces (2017). https://d oi.org/10.1002/admi.201700944.

97. M.F. Schatz and G.P. Neitzel, Annu. Rev. Fluid Mech. 33, 1 (2001).

98. V. Tallapally, R.J.A. Esteves, L. Nahar, and I.U. Arachchige, Chem. Mater. 28, 15 (2016). 
99. S. Majee, C. Liu, B. Wu, S.-L. Zhang, and Z.-B. Zhang, Carbon 114, 77 (2017). https://doi.org/10.1016/j.carbon.201 6.12.003.

100. K.Y. Shin, J.Y. Hong, and J. Jang, Adv. Mater. 23, 18 (2011).

101. S. Patchkovskii, J.S. Tse, S.N. Yurchenko, L. Zhechkov, T. Heine, and G. Seifert, Proc. Natl. Acad. Sci. U.S.A. 102, 30 (2005).

102. A. Geim, K. Novoselov, F. Schedin, S. Morozov, D. Jiang, and E. Hill, Nat. Mater. 6, 9 (2007).

103. V. Dua, S.P. Surwade, S. Ammu, S.R. Agnihotra, S. Jain, K.E. Roberts, S. Park, R.S. Ruoff, and S.K. Manohar, Angew. Chem. Int. Ed. 49, 12 (2010). https://doi.org/10.1002/a nie.200905089.

104. K. Müllen and J.P. Rabe, Acc. Chem. Res. 41, 4 (2008).

105. J. Wu, W. Pisula, and K. Müllen, Chem. Rev. 107, 3 (2007).

106. G. Eda and M. Chhowalla, Nano Lett. 9, 2 (2009).

107. P. Avouris, Z. Chen, and V. Perebeinos, Nat. Nanotechnol. 2, 10 (2007).

108. X. Wang, L. Zhi, and K. Müllen, Nano Lett. 8, 1 (2008).

109. J.M. Yun, J.S. Yeo, J. Kim, H.G. Jeong, D.Y. Kim, Y.J. Noh, S.S. Kim, B.C. Ku, and S.I. Na, Adv. Mater. 23, 42 (2011). https://doi.org/10.1002/adma.201102207.

110. X. Wen, J. Wu, D. Gao, and C. Lin, J. Mater. Chem. A 4, 35 (2016). https://doi.org/10.1039/c6ta04616a.

111. B. Joonho, P. Young Jun, L. Minbaek, C. Seung Nam, C. Young Jin, L. Churl Seung, K. Jong Min, and W.Z. Lin, Adv. Mater. 23, 30 (2011).

112. C. Liu, Z. Yu, D. Neff, A. Zhamu, and B.Z. Jang, Nano Lett. 10, 12 (2010). https://doi.org/10.1021/nl102661q.

113. W. Junbo, A. Mukul, H.A. Becerril, B. Zhenan, L. Zunfeng, C. Yongsheng, and P. Peter, ACS Nano 4, 1 (2010).

114. S. Bae, H.K. Kim, Y. Lee, X. Xu, J.S. Park, Y. Zheng, J. Balakrishnan, T. Lei, H.R. Kim, Y.I.I. Song, Y.J. Kim, K.S. Kim, B. Özyilmaz, J.H. Ahn, B.H. Hong, and S. Iijima, Nat. Nanotechnol. 5, 574 (2010). https://doi.org/10.1038/nnano. 2010.132.

115. F. Xia, T. Mueller, Y. Lin, A. Valdes-Garcia, and P. Avouris, Nat. Nanotechnol. 4, 839 (2009). https://doi.org/10. 1038/nnano.2009.292.

116. T. Echtermeyer, L. Britnell, P. Jasnos, A. Lombardo, R. Gorbachev, A. Grigorenko, A. Geim, A. Ferrari, and K. Novoselov, Nat. Commun. 2, 1 (2011).
117. G. Konstantatos, M. Badioli, L. Gaudreau, J. Osmond, M. Bernechea, G.D.A. Fp, F. Gatti, and F.H. Koppens, Nat. Nanotechnol. 7, 363 (2012). https://doi.org/10.1038/nnano. 2012.60 .

118. T. Mueller, F. Xia, and P. Avouris, Nat. Photon. 4, 5 (2010).

119. L. Yin, X. Tian, Z. Shang, and D. Li, Mater. Lett. 239, 132 (2018). https://doi.org/10.1016/j.matlet.2018.12.087.

120. T. Hasan, F. Torrisi, Z. Sun, D. Popa, V. Nicolosi, G. Privitera, F. Bonaccorso, and A.C. Ferrari, Phys. Status Solidi 247, 11-12 (2010).

121. Z. Sun, T. Hasan, F. Torrisi, D. Popa, G. Privitera, F Wang, F. Bonaccorso, D.M. Basko, and A.C. Ferrari, ACS Nano 4, 2 (2010). https://doi.org/10.1021/nn901703e.

122. W. Li, F. Li, H. Li, M. Su, M. Gao, Y. Li, D. Su, X. Zhang, and Y. Song, A.C.S. Appl. Mater. Interfaces 8, 19 (2016). h ttps://doi.org/10.1021/acsami.6b04235.

123. R. Beams, L. Gustavo Cancado, and L. Novotny, J. Phys.: Condens. Matter 27, 8 (2015).

124. N. Karim, S. Afroj, A. Malandraki, S. Butterworth, C. Beach, M. Rigout, K.S. Novoselov, A.J. Casson, and S.G. Yeates, J. Mater. Chem. C 5, 44 (2017).

125. S.S. Varghese, S. Lonkar, K.K. Singh, S. Swaminathan, and A. Abdala, Sens. Actuator B Chem. 218, 160 (2015). h ttps://doi.org/10.1016/j.snb.2015.04.062.

126. K.R. Ratinac, W.R. Yang, S.P. Ringer, and F. Braet, Environ. Sci. Technol. 44, 4 (2010).

127. G. Lu, L.E. Ocola, and J. Chen, Nanotechnology 20, 44 (2009). https://doi.org/10.1088/0957-4484/20/44/445502.

128. M.K. Choi, I. Park, D.C. Kim, E. Joh, O.K. Park, J. Kim, M. Kim, C. Choi, J. Yang, K.W. Cho, J.H. Hwang, J.M. Nam, T. Hyeon, J.H. Kim, and D.H. Kim, Adv. Funct. Mater. 25, 46 (2015). https://doi.org/10.1002/adfm.201570293.

129. K. Hu, D.D. Kulkarni, I. Choi, and V.V. Tsukruk, Prog. Polym. Sci. 39, 11 (2014). https://doi.org/10.1016/j.progpol ymsci.2014.03.001.

130. T. Premkumar and K.E. Geckeler, Prog. Polym. Sci. 37, 4 (2012).

Publisher's Note Springer Nature remains neutral with regard to jurisdictional claims in published maps and institutional affiliations. 